\title{
UM RETRATO EM PRETO E BRANCO DO SERTANEJO EM O QUINZE, DE RACHEL DE QUEIROZ
}

\section{A BLACK AND WHITE PORTRAIT OF THE BACKWOODSMAN IN $O$ QUINZE, BY RACHEL DE QUEIROZ}

\author{
Luan Alves Monteiro Carlos ${ }^{1}$ \\ Larissa Cristina Viana Lopes ${ }^{2}$ \\ Francisco Vieira da Silva ${ }^{3}$
}

\begin{abstract}
RESUMO: O objetivo deste artigo é discutir sobre o modo como o sertão é representado no romance $O$ Quinze (1930) de Rachel de Queiroz, bem como analisar o perfil dos personagens desta obra, compreendendo como estes reagem a uma situação de seca. Para realizarmos esse estudo, fundamentou-nos os estudos sobre sertanismo e regionalismo de Albuquerque Júnior (2011) e Almeida (1999), ancoramo-nos também em discussões sobre o romance de trinta a partir de Bueno (2015) e Bosi (1994). Esse trabalho lança um olhar analítico sobre o modo como Rachel de Queiroz retrata os diferentes tipos sociais que povoam o sertão por ela representado. Destarte, compreendemos que o sertão nordestino aparece como um dos protagonistas desta obra, sedo que o ambiente castigado pela seca participa de forma decisiva no destino de cada personagem, entendemos também que a falta de chuva desestrutura a vida de todos que habitam essa região, haja vista que os personagens das diferentes classes sociais vivem do cultivo da terra, assim ninguém fica isento das consequências da seca.
\end{abstract}

Palavras-chave: Regionalismo; Romance de trinta; O quinze; Literatura brasileira

ABSTRACT: The objective of this article is to discuss how the backwoods are represented in Rachel de Queiroz's novel O Quinze (1930), as well as to analyze the profile of the characters in this work, understanding how they react to a drought situation. In order to carry out this study, we have based the studies on sertanism and regionalism of Albuquerque Júnior (2011) and Almeida (1999), we also have anchors in discussions about the novel of thirty from Bueno (2015) and Bosi (1994). This work takes an analytical look at how Rachel de Queiroz portrays the different social types that populate the backwoods she represents. From this, we understand that the northeastern sertão appears as one of the protagonists of this work, I know that the environment punished by the drought plays a decisive role in the destiny of each character, we also understand that the lack of rain disrupts the lives of all that inhabit this region, since the characters of the

\footnotetext{
${ }^{1}$ Mestrando em Letras pelo Programa de Pós-Graduação em Letras (PPGL) da Universidade do Estado do Rio Grande do Norte - UERN: E-mail: luan_alvesmonteiro@ hotmail.com

${ }^{2}$ Doutoranda do Programa de Pós-Graduação em Estudos da Linguagem (PPgEL) da Universidade Federal do Rio Grande do Norte (UFRN). E-mail: larissavianalopes@ hotmail.com.

${ }^{3}$ Doutor em Linguística pela Universidade Federal da Paraíba (UFPB). Professor da Universidade Federal Rural do Semi-Árido (UFERSA), Campus Caraúbas. Rio Grande do Norte e do Programa de PósGraduação em Letras (PPGL) da Universidade do Estado do Rio Grande do Norte (UERN). E-mail: francisco.vieiras@ufersa.edu.br
} 
different social classes live from the cultivation of the land, so nobody is exempt from the consequences of the drought.

Keywords: Regionalism; Romance of thirty; O Quinze; Brazilian literature

Quando olhei a terra ardendo
Qual fogueira de São João
Eu perguntei a Deus do céu, ai
Por que tamanha judiação
Eu perguntei a Deus do céu, ai
Por que tamanha judiação
Que braseiro, que fornalha
Nem um pé de plantação
Por falta d'água perdi meu gado
Morreu de sede meu alazão
Por falta d'água perdi meu gado
Morreu de sede meu alazão
(Luiz Gonzaga)

\section{INTRODUÇÃO}

$\mathrm{Na}$ segunda geração do modernismo, período também conhecido como regionalismo de trinta, o sertão/sertanejo é mostrado com realismo. Assim, escritores desse período literário desenham um sertão e um sertanejo verossímil. Esse realismo se dá pelo fato de os romancistas terem consciência da vivência sertaneja e, assim, esse momento literário tem como principal característica o realismo das obras, o que vem junto com o caráter de denúncia social que os escritores imprimem em seus textos.

Dessa maneira, autores dessa época elucidam fatos por meio de seus personagens que mostram os problemas ambientais e sociais, que castigam o povo dessa região, colocando em evidência as especificidades da vida no sertão. A escritora Rachel de Queiroz faz parte desse momento literário, tendo como primeiro romance $O$ quinze (1930). Com essa obra a autora traz aos olhos dos leitores um sertão castigado pela seca e povoado por personagens que representam de forma verossímil os diversos tipos sociais que habitam essa região.

Dentro desta perspectiva, esta pesquisa busca compreender como o sertão é apresentado no romance $O$ quinze de Rachel de Queiroz. Para isso, desenvolveremos um estudo dos personagens, observando como se configura as vivências dos tipos sociais retratados pela autora e como estes lidam com a situação de seca, sendo a falta de chuva 
e suas consequências que devastam o sertão que impulsionam todo desenrolar do romance.

\section{Segunda geração do modernismo: anotações sobre a literatura regionalista de trinta}

O modernismo de 22 do século passado foi dominado por uma preocupação voltada mais ao estilo e à revolução na arte, enquanto que a partir de 1930, quando se inicia a Segunda Geração do Modernismo, os autores falam em seus textos de temas voltados para questões sociais, tentando mostrar a realidade vivida. Trata-se de uma fase que trouxe à literatura um "projeto ideológico", ideia compartilhada também por Bueno (2015), originando uma literatura engajada, que mostra questões da sociedade desconhecidas por muitos. Na geração de trinta os artistas destacam os problemas do Brasil.

É como se o modernismo se justificasse plenamente a partir de seu segundo momento. A eventual falta de seriedade do movimento expressa naquela imagem do garoto vaiando - se justifica diante do que ele permitiu que surgisse. Dessa forma, a geração de autores que apareceram nos anos de 30 é ao mesmo tempo herdeira e legitimadora do movimento de 22 , cuja grande contribuição foi abrir a porteira para o que se realisaria em seguida: os novos romances, os estudos sobre os problemas brasileiros (BUENO, 2015, p. 55).

O revolucinário primeiro momento do Modernismo é marcado pelo desejo de se fazer uma arte genuinamente brasileira propocionou que acontecesse no seu segundo momento, em trinta, essa tomada de conciência dos problemas que afetavam as diversas regiões do Brasil, surgindo assim o regionalismo de trinta, destacando especificidades de cada região.

Em trinta, "Os escritores agora parecem mais preocupados com o questionamento direto da realidade do que com a renovação da linguagem narrativa" (ALMEIDA, 1999, p.204). No regionalismo dessa época, escritores ressaltaram em suas obras as especificidades de cada região. Neste viés, o romance nordestino assume uma posição de destaque em que os autores, naturais da região, voltaram seus romances para questões sociais situadas, entre outros, no sertão nordestino, trazendo obras ambientanas no Nordeste com o sertanejo e suas famílias como protagonistas. 
O Nordeste ganha grande evidência no regionalismo de trinta, trazendo à tona problemas sociais que afetam a vida do povo sertanejo, mostrando uma visão da realidade vivida nessa região (apesar de haver outras regiões retratadas em várias obras).

O final da década de vinte e, principalmente, a década de trinta marcam a transformação da literatura regionalista em "literatura nacional". A emergência da análise sociológica do homem brasileiro, como uma necessidade urgente, colocada pela formação discursiva nacionalpopular, dá ao romance nordestino o estatuto de uma literatura preocupada com a nação e com seu povo, mestiço, pobre, inculto e primitivo em suas manifestações sociais. A literatura passa a ser vista como destinada a oferecer sentido às várias realidades do país; a desvendar a essência do Brasil real (ALBUQUERQUE JÚNIOR, 2011, p.123).

Como diz o autor, a literatura regionalista implica uma conciência nacional por falar de temas específicos da nossa terra, fazendo uma análise das diversas realidades do nosso país e do seu povo, mostrando o modo de viver das distintas regiões do Brasil. O romance nordestino aparece preocupado com as diferentes realidades do sertanejo, o rico e o pobre, os opressores e os oprimidos. Destarte, a literatura vem mostrar as especificidades de cada região do país, desbravando um Brasil real.

O próprio surgimento do que passa a ser chamado de "romance de trinta" ter-se-ia dado pela identificação completa dos autores com sua paisagem, com seu meio, passando a senti-lo, a vê-lo, a dizê-lo como nunca se fizera antes. Para Paulo Cavalcante, esse romance expressava uma realidade coletiva, fiel às tendências de um povo e às características de uma região, relacionando as lembranças dos autores ao que havia de mais essencial na estrutura da sociedade. Uma literatura verdadeiramente brasileira por estar ligada à região que menor influência estrengeira havia sofrido e também por ser a síntese de todas as suas contradições, os contrastes sociais e naturais (ALBUQUERQUE JÚNIOR, 2011, p.124).

Muitos autores dessa geração olharam para sua terra natal, apresentando uma realidade que, na maioria das vezes, vivenciaram ou ouviram seus familiares falarem sobre temas regionais. Escritores dessa fase modernista sentiram a necessidade de mostrar um Brasil desconhecido por muitos, para isso pintaram o sertão nordestino real com seus sabores e dissabores. O sertão aparece no regionalismo como uma região "pura", isso por 
ter recebido menos influências estrangeiras e isso justifica a consciência nacional que houve por meio da literatura sertanista.

A autora Rachel de Queiroz retratou em $O$ quinze (1930) a grande seca de 1915, que deixou marcas na vida do povo cearense. Ela, natural do Ceará, destacou em sua obra como ricos e pobres reagiram a essa seca. Esse retorno dos autores, como a cearense, para suas raízes, deu-se pelo desejo de representar a realidade de uma maneira objetiva, sendo as principais inspirações as lembranças, trazendo uma descrição fiel da paisagem e da população. Eis um convite para conhecermos a fundo $O$ quinze no tópico seguinte, em que será feito um estudo detalhado sobre os sertanejos retratados na obra, observando a forma como pessoas de classes sociais distintas enfrentaram uma das maiores secas que o sertão já passou.

\section{A seca retratada pelo olhar realista de Rachel de Queiroz em $O$ Quinze}

No seu romance de estreia, $O$ quinze, a jovem escritora comove por sua maneira realista de falar sobre o sertão nordestino, destacando os problemas naturais e sociais que afetam a região, colocando em palavras o sofrimento que ela pouco viu, mas que ouvia falar sobre uma seca que marcou época, a grande seca de 1915, lembrada com muita dor por quem a vivenciou.

Em 1915, a família, que há dois anos voltara a morar em Fortaleza, testemunha uma das maiores e mais devastadoras secas já havidas no Ceará (assim como outra, tão implacável quanto, em 1919), experiência que marcaria fundo o espírito e a memória da futura romancista. Mal vencida a adolescência, Rachel transformaria aquelas fortes lembranças na literatura de $O$ Quinze, como os cearenses se referiam ao flagelo por que passaram naquele ano (CAMINHA, 2010, p. 7).

Sua família tendo vivenciado a catástrofe que foi essa seca, inspirou a autora a falar sobre essa realidade do Nordeste no sertão, que precisava ser vista e ouvida por outras pessoas. A narrativa indica como a seca atingiu as diferentes classes sociais que vivem no sertão e, mais do que isso, como cada tipo social reagiu e vivenciou esse momento difícil, época de grandes dificuldades, o que deixa transparecer o que o ser humano tem de melhor e pior. 
O romance já começa com a ameaça da chegada da seca e a experiência do povo do sertão já o faz perceber a aproximação de tempos difíceis. Conceição, ao observar o céu, coloca em prática sua experiência de sertaneja, compreende o tempo e constata “Eh! Lua limpa, sem lagoa! Chove não!...” (QUEIROZ, 2004, p. 12). Logo no início do romance, a fé de Conceição e dona Inácia se mostra como o maior refúgio para elas enfrentarem esse tempo difícil que se anuncia. Mulheres boas e de alma caridosa assistem e vivem a seca, sofrendo com cada um dos flagelados e animais que não tinham o que comer. Mesmo em um lugar com tanta miséria, a condição financeira delas as colocava em uma situação confortável, mas ambas não se acomodavam, ajudando como podiam aos menos favorecidos, na esperança de dias melhores.

Vicente é também pertencente à classe social alta e mostra verdadeira paixão pela natureza e pelos animais (famintos), mesmo passando por diversas dificuldades faz de tudo para manter os bichos vivos e ajuda como pode os necessitados. Ele aparece como um sertanejo inato que não desiste do sertão e honra a vida que leva, provando que não é só uma questão de lucrar com o que faz, porém, uma maneira de viver e isso faz dele um verdadeiro "homem da terra" que não desiste diante das adversidades. Esse seu comprometimento e seu lado humano aparecem desde o início do romance, quando cuida do gado já com os recursos escassos e pensa como enfrentar o tempo ruim que vem chegando:

Encostado a uma jurema seca, defronte ao juazeiro que a foice dos cabras ia pouco a pouco mutilando, Vicente dirigia a distribuição de rama verde ao gado. Reses magras, com grandes ossos agudos furando o couro das ancas, devoravam confiadamente os rebentões que a ponta dos terçados espalhava pelo chão.

Era raro e alarmante, em março, ainda se tratar de gado. Vicente pensava sombriamente no que seria de tanta rês, se de fato não viesse o inverno. A rama já não dava nem para um mês (QUEIROZ, 2004, p.14$15)$.

As primeiras consequências da seca já brotam e podem ser vistas na aparência do gado magro. Vicente os alimenta pensando no que vai fazer para atravessar esses tempos difíceis e salvar tanta rês, o dilema do sertanejo é saber qual é a forma de salvar o máximo de rês possível. Pensa em levar os animais para a serra, mas sabe que lá também o tempo é de dificuldade, não estando nenhum lugar no sertão isento da catástrofe que se anunciava. Ao observar a situação dos animais cobertos de carrapato e diante de uma seca que já era certa, o vaqueiro chega a se lastimar pensando no que vai vir pela frente. 
Vicente lastimou-se:

- Inda por cima do verãozão, diabo de tanto carrapato... Dá vontade é de deixar morrer logo!

- Por falar em deixar morrer... O compadre já soube que dona Maroca das Aroeiras deu ordem pra, se não chover até o dia de São José, abrir as porteiras do curral? E o pessoal dela que ganhe o mundo... Não tem mais serviço pra ninguém.

Escandalizado, indignado, Vicente saltou de junto da jurema onde se encostava:

- Pois eu, não! Enquanto houver juazeiro e mandacaru em pé e água no açude, trato do que é meu! Aquela velha é doida! Mal empregado tanto gado bom!

E depois de uma pausa, fitando um farrapo de nuvem que se esbatia no céu longínquo:

- E se a rama faltar, então, se pensa noutra coisa. Também não vou abandonar meus cabras numa desgraça dessas... Quem comeu carne tem que roer os ossos... (QUEIROZ, 2004, p.15-16).

Ao pensar na situação que se encontra o gado e no verão, Vicente prevê o trabalho que vai ter numa batalha quase que já perdida para a seca. Por um instante, sente vontade de largar tudo aquilo, sendo isso mais um pensamento de momento do que uma vontade, mas ao saber que a dona Maroca tinha ordenado seu vaqueiro se a chuva não chegasse, o sertanejo se revolta e mostra que não desiste do sertão, do que é seu, disposto a sofrer até as últimas consequências sem desistir da vida sertaneja, que é sua essência.

Dona Maroca aparece como o oposto de Vicente, pois age cruelmente, mostrando que seu único interesse era o lucro, uma personagem que se apresenta de uma maneira muito desumana com sua atitude de se desfazer do gado, pois além de uma crueldade com os animais, atinge diretamente a vida do vaqueiro Chico Bento e sua família, que perdem seu meio de vida. Mas Vicente, dono de uma grande fazenda, assim como dona Maroca, age comprometido com a natureza e com seus trabalhadores, honrando a vida que leva, mostrando-se um sertanejo por natureza.

Albuquerque júnior (2011, p.162) fala dessas características do sertanejo inato que Rachel tão bem representou com o personagem Vicente.

Vicente, de $O$ Quinze, é exemplo deste homem quase natureza, "bom de se ver e de se ouvir como uma bela paisagem, de quem só se exigisse beleza e cor", um sertanejo puro, viril, "de uma fortaleza quase animal". Homem capaz de construir seu espaço, de reconstruir a natureza à sua imagem e semelhança; homem e natureza se reencontrando sem a separação produzida pela modernidade. Um homem capaz de entender a natureza e ser entendido por ela. Homem bom e paternalista, que 
protege os mais fracos, que respeita a família, que vê o mundo a partir dos valores tradicionais sertanejos. Sertão do respeito filial dos empregados aos patrões, das senhoras carregadas de cadeirinha por seus moradores, da terra que se ama como um corpo querido, mas que também possuía males como a seca, a fome, o desprezo, a doença, as longas existências miseráveis.

$\mathrm{O}$ autor ressalta essa entrega que o personagem tem para a vida no campo, como um sertanejo genuíno, que nasceu para isso e não sabe viver de outra forma, que sabe compreender a natureza e viver em harmonia com ela. Que mantém vivo os valores do sertão, respeitando e ajudando os que precisam, sabendo lidar com os empregados, com a família e com a natureza em tempo de fartura e de escassez.

O cenário da seca acompanha os personagens por toda a obra, sendo o ambiente um verdadeiro protagonista. A autora cearense descreve minuciosamente o ambiente em que as ações se passam, desde as questões climáticas até a miséria que tomava conta do sertão. A descrição do ambiente, então, é fundamental para retratar com realismo o que se passou naquela seca. A modificação do ambiente pode ser comprovada nessa passagem que traz uma viagem de Vicente a casa de dona Inácia:

\footnotetext{
Novamente a cavalo no pedrês, Vicente marchava através da estrada vermelha e pedregosa, orlada pela galharia negra da caatinga morta. Os cascos do animal pareciam tirar fogo nos seixos do caminho. Lagartixas davam carreirinhas intermitentes por cima das folhas secas no chão que estalavam como papel queimado.

O céu, transparente que doía, vibrava, tremendo feito uma gaze repuxada.

Vicente sentia por toda parte uma impressão ressequida de calor e aspereza.

Verde, na monotonia cinzenta da paisagem, só algum juazeiro ainda escapo à devastação da rama; mas em geral as pobres árvores apareciam lamentáveis, mostrando os cotos dos galhos como membros amputados e a casca toda raspada em grandes zonas brancas.

E o chão, que em outro tempo a sombra cobria, era uma confusão desolada de galhos secos, cuja agressividade ainda mais se acentua pelos espinhos (QUEIROZ, 2004, pp. 17-18).
}

Por meio do olhar verticalizado da autora, podemos constatar e sentir o ambiente desolador em que se transforma o sertão em época de seca, com a morte como parte do cenário, sendo vista por todo lado em um lugar cinzento composto por árvores e animais mortos, galhos e ossos secos queimados pelo sol, encontrados por toda parte. O sol e a quentura aparecem de uma maneira insuportável que chega a nos fazer confundi-los com 
fogo queimando as pessoas e toda a vegetação, formando uma "caatinga morta", como a própria autora coloca.

Em meio a tudo isso, só o sertanejo, acostumado com o sol do Nordeste, e o juazeiro, a única árvore que resiste a seca conservando o mesmo verde da época de inverno, o que a faz se destacar entre uma paisagem cinza, mantêm-se vivos, conseguindo resistir às adversidades do sertão.

A família de Chico Bento, retirantes vítimas dessa cruel realidade, seguem sem perspectiva nenhuma na saga do sertanejo que, assim como muitos outros, sai de sua terra em meio a caatinga, trilhando um caminho miserável, em busca de um lugar melhor onde pudessem viver de maneira digna. No caminho, diferente do que ele e a família idealizaram, a miséria foi o que mais encontraram, testemunhando o desespero da fome, da sede, das doenças e da morte, consequências de uma seca impiedosa da qual tentavam fugir.

Essa família de flagelados, em meio a tantas outras, carregando somente a esperança de encontrar melhores condições de vida, são vítimas das mais perversas consequências. A morte de um dos seus filhos, Josias, demonstra bem o sofrimento que essa família passou no sertão, sendo essa morte resultado de toda calamidade que passavam, o momento máximo do sofrimento em que se encontravam. Com muita fome, Josias decide comer mandioca crua, o que é uma substância venenosa, e, ao ficar doente, a família faz o que pode para salvá-lo, mas seu destino, assim como o de muitos que viram na estrada morrendo por consequência da seca, também foi a morte. Ali a seca fez somente mais uma vítima fatal, entre tantas incontáveis, que enseja um enterro improvisado pela família e uma descrição da morte como um descanso para uma alma sofredora.

Lá se tinha ficado o Josias, na sua cova à beira da estrada, com uma cruz de dois paus amarrados, feita pelo pai.

Ficou em paz. Não tinha mais que chorar de fome, estrada afora. Não tinha mais alguns anos de miséria à frente da vida, para cair depois no mesmo buraco, à sombra da mesma cruz (QUEIROZ, 2004, p.67).

Esse momento de tensão máxima em que um dos filhos do retirante perdera a vida, resultado da vida desumana que enfrentava, assinala uma dura realidade do sertão, em que o sertanejo que vive do trabalho com o campo enfrenta uma realidade difícil, a qual, muitas vezes, obriga-o a migrar, como Chico Bento, enfrentando, assim, um destino de 
sofrimento. Mas como fica esclarecido no fragmento transcrito acima, o sofrimento de Josias foi reduzido, afinal, para que viver mais anos se cairia no mesmo buraco? Se teria esse mesmo fim? Essa morte é vista como um descanso para Josias, pois seu sofrimento acabou.

O outro filho do casal, o Duquinha, teve um destino diferente graças a sua madrinha, a bondosa Conceição, que pegou o menino para criar ao vê-lo muito debilitado, em uma situação desumana, só um milagre e os cuidados da madrinha poderiam salvá-lo.

- Trinta e nove e meio!

Conceição perguntou:

- Morre, doutor?

- Não sei... Esses meninos da seca são tão milagrosos que às vezes escapam...

E apalpando os bracinhos ressequidos como asas depenadas, as pobres perninhas atrofiadas:

- Mas também que esqueleto a senhora foi arranjar! (QUEIROZ, 2004, p. 111).

No diálogo, podemos ver que o físico da criança é uma imagem atrofiada o que traduz o sofrimento no corpo dos mais pobres, que não tinham recursos nem para a alimentação. Tal imagem comprova o ambiente de miséria que tomava conta do sertão, onde a morte cada vez mais se fazia presente, vitimando os retirantes que se transfiguravam por fora, mas guardando uma força imensa por dentro, para lutar por vida contra uma seca que só lhes oferecia a morte. O Duquinha resistiu.

No final do romance, com a vida do sertão já completamente devastada por uma seca impiedosa, as primeiras chuvas começam a cair e dona Inácia, a qual tinha ido morar com Conceição em Fortaleza na época de seca, decide voltar para o Logradouro.

$\mathrm{Na}$ estrada já podia ser visto o ambiente mudando, o verde voltava a fazer parte da paisagem do sertão, entretanto as marcas da seca ainda permaneciam, pois para recuperar a vida que a seca levou ainda necessitava de tempo. A chegada de dona Inácia à sua casa comprova a falta de vida, porquanto, mesmo com chuva e o verde das plantas, a morte ainda fazia parte do ambiente sertanejo:

Ao ver sua casa, o curral vazio, o chiqueiro da criação devastado e em silêncio, a vida morta, apesar do lençol verde que tudo cobria, dona Inácia amargamente chorou, com a mesma desesperada aflição de quem encontra o corpo de alguém muito querido, que durante nossa ausência morreu (QUEIROZ, 2004, pp. 152-153). 
Apesar dos benefícios já trazidos pela chuva, no sertão a situação continuou difícil, pois a seca tinha devastado tudo e deixado marcas profundas na natureza e na vida dos que ali viviam. As feridas abertas pela seca eram profundas na natureza e na alma dos que a vivenciaram, feridas que podem cicatrizar, mas as marcas da seca miserável evidenciam sofrimentos passados que deixam seus rastros. $\mathrm{O}$ ambiente não era o mesmo, estava morto, querendo reviver, mas ainda morto, e o povo que habita esse lugar iria viver o luto de todas aquelas perdas e tentar se recuperar para seguir em frente, pessoas que já não eram mais as mesmas de antes de 1915.

\section{CONSIDERAÇÕES FINAIS}

Rachel de Queiroz, na obra estudada neste estudo, refletiu sobre o sertão e seu povo por meio de uma representação fiel do ambiente e de figuras humanas, tendo como protagonistas figuras marginalizadas fadadas a um caminho de fracasso (Chico Bento e sua família), mas também trouxe à baila personagens donos de fazendas, possuidores de um bom posicionamento social (Vicente, dona Maroca, Conceição e dona Inácia). Assim, a autora apresenta classes sociais distintas diante da seca, apresentando um verdadeiro retrato do sertão, percebemos por meio dos tipos sociais representados que a seca atinge a todos, não ficando ninguém isento do sofrimento causado pela falta de chuva.

Fica evidente que a condição de fracassado da família de Chico Bento não era um resultado pessoal, pois se trata de um fenômeno climático que os levou a isso, eram personagens levados ao fracasso sem culpa. No que se referem aos demais personagens, esses, apesar de possuírem uma vida bem-sucedida também passam por uma forte desestruturação, sendo que no sertão a economia é abastecida pela agricultura, assim a autora reflete sobre a forma como a seca castiga a todos no sertão. Por meio de dramas sociais que castigam a vida do sertanejo, a escritora traz em sua arte um tom de denúncia, falando de temas naturais e sociais que assolam o sertão cearense. Nesse romance, a autora dá voz ao povo enquanto população oprimida, que necessitava ser vista e ouvida. Ela cria tipos sociais por meio de seus personagens, os quais representam toda uma classe.

Destarte, a jovem escritora de $O$ quinze mostrou sua essência com sua forma forte, direta e natural de escrever, características que puderam ser observadas ao longo de sua produção, sempre tratando sobre problemas que assolam nossa sociedade, fazendo uma 
literatura engajada que traz à tona uma realidade de denúncia, num retrato em preto e branco que traduz as agruras do sertão.

\section{REFERÊNCIAS}

ALBUQUERQUE JÚNIOR, Durval Muniz de. A Invenção do Nordeste e Outras Artes. São Paulo: Cortez, 2011.

Nordestino: invenção do "falo" - uma história do gênero masculino (1920-1940). São Paulo: Intermeios, 2013.

ALMEIDA, José Maurício Gomes de. A Tradição Regionalista no Romance Brasileiro. Rio de Janeiro: Topbooks Editora, 1999.

BOSI, Alfredo. História Concisa da Literatura Brasileira. São Paulo: Editora Cultrix, 1994.

BUENO, Luís. Uma História do Romance de 30. São Paulo: Editora da Unicamp, 2015.

CAMINHA, Edmílson. Rachel de Queiroz: a senhora do não me deixes. Rio de Janeiro: Academia Brasileira de Letras, 2010.

GONZAGA, Luiz. Asa Branca. Disponível em: < https://www.vagalume.com.br/luizgonzaga/asa-branca.html> Acesso em 20 nov. 2017.

QUEIROZ, Rachel de. O Quinze. Rio de Janeiro: José Olympio, 2004.

Recebido em: 19 abr. 2018

Aceito em: 25 mai. 2018 